\title{
The Development and Validation of a Stability-Indicating UHPLC-DAD Method for Determination of Perindopril L-Arginine in Bulk Substance and Pharmaceutical Dosage Form
}

\author{
Magdalena Paczkowska • Przemysław Zalewski • \\ Piotr Garbacki • Alicja Talaczyńska • Anna Krause • \\ Judyta Cielecka-Piontek
}

Received: 31 March 2014 / Revised: 26 May 2014 / Accepted: 20 June 2014 / Published online: 13 August 2014

(C) The Author(s) 2014. This article is published with open access at Springerlink.com

\begin{abstract}
A stability-indicating ultra-high-performance liquid chromatography (UHPLC) method with a diode array detector was developed and validated for the determination of cis/trans isomers of perindopril $\mathrm{L}$-arginine in bulk substance and pharmaceutical dosage form. The separation was achieved on a Poroshell 120 Hilic $(4.6 \times 150 \mathrm{~mm}$, $2.7 \mu \mathrm{m})$ column using a mobile phase composed of acetonitrile- $0.1 \%$ formic acid $(20: 80 \mathrm{v} / \mathrm{v})$ at a flow rate of $1 \mathrm{~mL} \mathrm{~min}^{-1}$. The injection volume was $5.0 \mu \mathrm{L}$ and the wavelength of detection was controlled at $230 \mathrm{~nm}$. The selectivity of the UHPLC-DAD method was confirmed by determining perindopril L-arginine in the presence of degradation products formed during acid-base hydrolysis and oxidation as well as degradation in the solid state, at an increased relative air humidity and in dry air. The method's linearity was investigated in the ranges $0.40-1.40 \mu \mathrm{g} \mathrm{mL}-1$ for isomer I and $0.40-2.40 \mu \mathrm{g} \mathrm{mL}^{-1}$ for isomer II of perindopril L-arginine. The UHPLC-DAD method met the precision and accuracy criteria for the determination of the isomers of perindopril L-arginine. The limits of detection and quantitation were 0.1503 and $0.4555 \mu \mathrm{g} \mathrm{mL}^{-1}$ for isomer I and 0.0356 and $0.1078 \mu \mathrm{g} \mathrm{mL}^{-1}$ for isomer II, respectively.
\end{abstract}

Published in the topical collection Advances in Chromatography and Electrophoresis \& Chiranal 2014 with guest editor Jan Petr.

M. Paczkowska $(\bowtie) \cdot$ P. Zalewski · P. Garbacki · A. Talaczyńska J. Cielecka-Piontek

Department of Pharmaceutical Chemistry, Faculty of Pharmacy, Poznan University of Medical Sciences, Grunwaldzka 6,

60-780 Poznan, Poland

e-mail: magda.paczkowska@gmail.com

A. Krause

PozLab sp.z.o.o, Poznan, Poland
Keywords UHPLC-DAD · Perindopril · cis-trans isomers $\cdot$ Stability

\section{Introduction}

Perindopril $\quad((2 S, 3 \mathrm{a} S, 7 \mathrm{a} S)-1-[(2 S)-2-[[(2 S)-1$-ethoxy-1-oxopentan-2-yl]amino]propanoyl]-2,3,3a,4,5,6,7,7a-octahydroindole-2-carboxylic acid) is a long-acting angiotensinconverting enzyme (ACE) inhibitor which is effective in reducing blood pressure and improving outcomes in a number of cardiovascular diseases [1]. Perindopril is a prodrug ester which was observed to convert to diacid perindoprilat, an active metabolite, during in vivo studies [2]. Currently, two salts of perindopril, erbutamine (tert-butylamine) and L-arginine, are used therapeutically [3]. Both salts are chemically unstable and undergo degradation in dosage forms to other diacids and diketopiperazines [4]. Perindopril L-arginine is the first ACE inhibitor analog which contains only a stereoselective $S$ enantiomers. Due to the presence of a double bond in the tertiary amide bond of the C-terminal proline containing a peptide bond, perindopril can exist in the form of cis/trans isomers (Fig. 1).

Only several HPLC-DAD methods have been reported for the determination of perindopril in the presence of its degradation products and synthesis-induced impurities [5, 6]. Since combinations of perindopril with drugs from other groups such as calcium channel blockers or diuretics are used in hypertension therapies, HPLC-DAD methods for the determination of perindopril in the presence of other drugs in pharmaceutical preparations and in body fluids have been reported as well [7, 8]. Chromatographic techniques have also been applied to investigate separation between the cis and trans isomers of perindopril. Stability studies of perindopril supported by a theoretical approach showed that the 


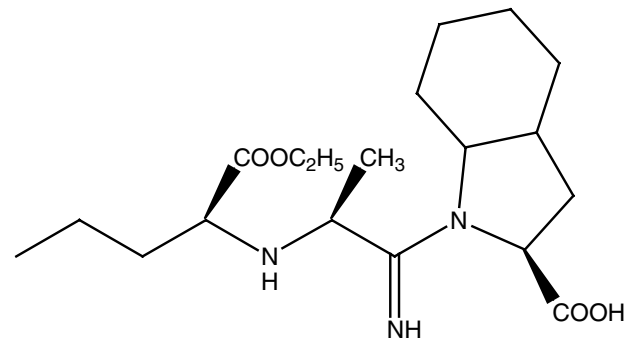

trans

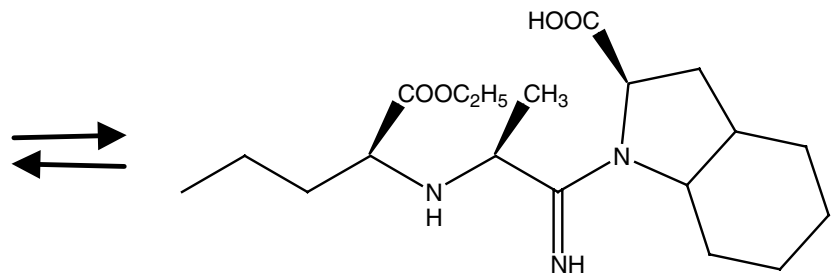

cis

Fig. 1 Chemical structure of cis/trans isomers of perindopril

type of salt and the compound charge have an impact on its degradation, proving perindopril $\mathrm{L}$-arginine to be more stable than erbutamine salt $[9,10]$. No procedures based on UHPLC solutions for the determination of perindopril have been reported. However, the application of UHPLC method in perindopril determination, with reduction of analysis time with the possibility of a reliable separation of its isomers, meets the criteria of modern analytical techniques.

Therefore, the aim of our study was to develop a UHPLC-DAD method allowing separation of the cis and trans isomers in bulk substances and pharmaceutical dosage forms (Prestarium ${ }^{\circledR}$ ), and to investigate their degradation under the influence of stress factors.

\section{Experimental}

Chemicals, Reagents, and Solutions

Perindopril L-arginine (purity $>98 \%$ ) in bulk substance was applied by India PVT LTD., while Prestarium ${ }^{\circledR}$, containing racemic mixture of cis/trans isomers (10 $\mathrm{mg}$ coated tablets), was a commercial preparation manufactured by Servier. Hydrochloric acid, sodium hydroxide solution, hydrogen peroxide and all other chemicals were obtained from P.O.Ch. (Gliwice, Poland). Acetonitrile of an HPLC grade was supplied by Merck KGaA (Darmstadt, Germany) and formic acid $(100 \%)$ by P.O.Ch. (Gliwice, Poland). Ultrapure water $\left(18 \mathrm{M} \Omega \mathrm{cm}\right.$ at $\left.25^{\circ} \mathrm{C}\right)$ was prepared using an Exil SA 67120 Millipore purification system (Molsheim, France).

\section{Chromatographic Equipment}

The LC system (Dionex Thermoline Fisher Scientific, Schwerte, Germany) was equipped with a high pressure pump (UltiMate 3000), an autosampler (UltiMate 3000) and a DAD detector (UltiMate 3000). For data processing and acquisition, Chromeleon software version 7.0 from Dionex Thermoline Fisher Scientific (US) was used. As the stationary phase, a Poroshell 120 Hilic column, $2.7 \mu \mathrm{m}$ particle size, $4.6 \times 150 \mathrm{~mm}$ (containing ultra-high purity silica, $99.995 \% \mathrm{SiO}_{2}$ ) (Agilent Technology, Santa Clara, US) was used. The mobile phase consisted of acetonitrile- $-0.1 \%$ formic acid $(20: 80 v / v)$. The flow rate of the mobile phase was $1.0 \mathrm{~mL} \mathrm{~min}{ }^{-1}$. The wavelength of the UV detector was set at $230 \mathrm{~nm}$. The injection volume was $5.0 \mu \mathrm{L}$. The column temperature was $25{ }^{\circ} \mathrm{C}$. Chromatographic separation was performed with a pressure of 420 bars. $\mathrm{PH}$ of mobile phase was measured by $\mathrm{pH}$-meter (Mettler Toledo SevenCompact pH/Ion S220, Warsaw, Poland).

\section{Method Validation}

The method was validated according to the International Conference on Harmonization Guidelines [11]. It comprised selectivity, linearity, accuracy, precision, limits of detection (LOD) and quantitation (LOQ). All measurements were performed in triplicates.

\section{Sample Solutions}

Sample solution of perindopril L-arginine was prepared by dissolving $10.0 \mathrm{mg}$ of perindopril $\mathrm{L}$-arginine in $25.0 \mathrm{~mL}$ of ultrapure water. Prestarium ${ }^{\circledR}$, commercially available dosage form of perindopril L-arginine, was pounded and weighed mass of the appropriate $10.0 \mathrm{mg}$ of perindopril $\mathrm{L}$-arginine and dissolved in $25.0 \mathrm{~mL}$ of ultrapure water.

\section{Selectivity}

The selectivity of determination of perindopril L-arginine was examined for non-degraded and degraded samples. The selectivity of perindopril L-arginine determination was established in the presence of excipients (lactose monohydrate, magnesium stearate). While the selectivity of perindopril L-arginine determination in degraded samples was examined in the presence of degradation products formed during acidic-basic hydrolysis (in hydrochloric acid (1 M) at $353 \mathrm{~K}$ and in solution of sodium hydroxide $(1 \mathrm{M})$ at $353 \mathrm{~K})$, oxidation $\left(10 \% \mathrm{H}_{2} \mathrm{O}_{2}\right.$ at $\left.353 \mathrm{~K}\right)$ and thermolysis 

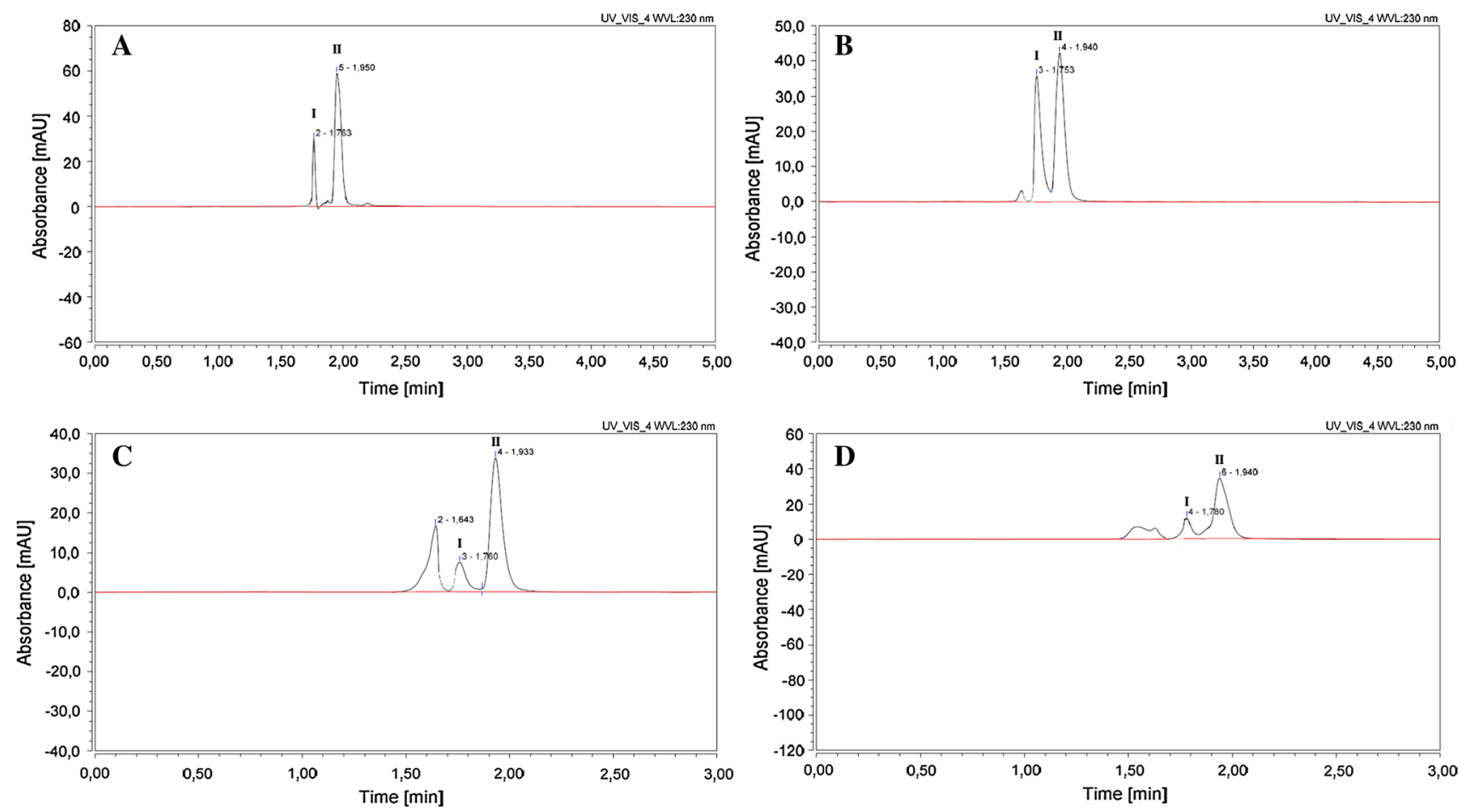

Fig. 2 The chromatogram of isomer $\mathrm{I}\left(t_{\mathrm{R}}=1.763 \mathrm{~min}\right)$ and isomer II $\left(t_{\mathrm{R}}=1.950 \mathrm{~min}\right)$ of perindopril L-arginine: in bulk substance (a); in pharmaceutical dosage form Prestarium ${ }^{\circledR}(\mathbf{b})$; in degraded samples

in $\mathrm{HCl}(1 \mathrm{M}, T=353 \mathrm{~K}$, content of initial concentration $39 \%)(\mathbf{c})$; in degraded samples in $\mathrm{NaOH}(1 \mathrm{M}, T=353 \mathrm{~K}$, content of initial concentration $33 \%)(\mathbf{d})$

(at an increased relative air humidity $76.4 \% \mathrm{RH}$ at $353 \mathrm{~K}$ and in dry air $0 \% \mathrm{RH}$ at $373 \mathrm{~K}$ ).

\section{Precision}

Precision of the assay was determined in relation to repeatability (intra-day) and intermediate precision (inter-day) at three levels of concentration: $80 \%\left(1.6 \mu \mathrm{g} \mathrm{mL}^{-1}\right), 100 \%$ $\left(2.0 \mu \mathrm{g} \mathrm{mL}^{-1}\right)$ and $120 \%\left(2.4 \mu \mathrm{g} \mathrm{mL}^{-1}\right)$. Every sample was injected six times.

\section{Accuracy}

The accuracy of the method was determined by recovering perindopril L-arginine from placebo. As placebo substance was chosen talc. The accuracy was established at three levels 80,100 and $120 \%$ of label claim of the substance for determination of perindopril L-arginine in bulk substance and in pharmaceutical dosage form.

\section{The Limit of Detection (LOD) and Quantification (LOQ)}

LOD and LOQ parameters were determined from the regression equations of perindopril L-arginine. $\mathrm{LOD}=3.3$ $S_{y} / a, \mathrm{LOQ}=10 S_{y} / a$; where $S_{y}$ is a standard error and $a$ is the slope of the corresponding calibration curve.

\section{Robustness}

The impact of the percentage of acetonitrile in the mobile phase, $\mathrm{pH}$ of mobile phase, the flow rate and the column temperature on the peak area and shape of perindopril L-arginine were determined.

\section{Standard Solution}

Standard stock solution of perindopril L-arginine was prepared by dissolving $10.0 \mathrm{mg}$ of perindopril L-arginine in $25.0 \mathrm{~mL}$ of ultrapure water. Standard stock solution was kept during period of studies.

\section{Results and Discussion}

The UHPLC procedure was optimized with a view to developing a method for stability-indicating assay of perindopril L-arginine and separation of its cis and trans isomers in bulk substance and pharmaceutical dosage form. Under the optimized chromatographic conditions, two peaks for non-degraded samples of perindopril L-arginine were recorded. As shown by the chromatograms, isomers $\mathrm{I}$ and II of perindopril $\mathrm{L}$-arginine were eluted at retention times $t_{\mathrm{R}}=1.76$ and $t_{\mathrm{R}}=1.95$, respectively (Fig. 2a). On 
the chromatograms of the degraded samples of perindopril L-arginine a decrease was observed in the peaks of the isomers and the appearance of peaks related to the degradation products was registered. The spectrophotometric purities of peaks of main substance in the presence of its degradation products were confirmed. Perindopril L-arginine was subjected to acidic, basic, thermal, photolytic, and oxidative stress conditions according to ICH regulations. Different rates of degradation were observed for the isomers depending on the stress factors applied. The peak tailing factors for the isomers of perindopril L-arginine were between 1.37 and 1.64. The chromatograms of non-degraded and degraded samples of perindopril $\mathrm{L}$-arginine are shown in Fig. 2a-d. In a previous investigation, Bouabdallah et al. [5] confirmed the effect of organic solvent, $\mathrm{pH}$, temperature, $\beta$-cyclodextrins and flow rate on the possibility of separating the cis/trans isomers of perindopril L-arginine when the chromatographic procedure was based on a column with $5 \mu \mathrm{m}$ particle size. The isomers of perindopril L-arginine were eluted at 2.14 and $3.88 \mathrm{~min}$. However, the isomers of perindopril L-arginine were better separated and in a shorter time when the UHPLC-DAD method described in the present work was applied.

The method was validated for selectivity, linearity, interand intra-day accuracy and precision, robustness, system suitability, LOD, LOQ and recovery for the assay of perindopril L-arginine in the pharmaceutical preparation Prestarium $^{\circledR}$. All validation parameters were established for the cis/trans isomers of perindopril L-arginine. The calibration plots were linear in concentration of isomer $\mathrm{I}$ in the range $0.40-1.40 \mu \mathrm{g} \mathrm{mL}^{-1}(n=11, r=0.9914)$ and isomer II $0.40-2.40 \mu \mathrm{g} \mathrm{mL}^{-1}(n=11, r=0.9998)$. They were described by the equations $y=a x: y=(0.2143 \pm 0.0394) x$ for isomer I and $y=(1.7652 \pm 0.0266) x$ for isomer II. The $b$ values, calculated from the equation $y=a x+b$, were insignificant because of being lower than the critical value $t_{b}=b / S_{b}$ (Table 1$)$. The values of RSD for the determination of the isomers during the evaluation of intra-day precision ranged from 0.89 to $1.91 \%$ for isomer I and from 1.06 to $1.98 \%$ for isomer II. The ranges of inter-day determination were $1.04-1.71$ and $1.20-1.80 \%$ for isomers I and II, respectively. The accuracy of determination, established at 80,100 and $120 \%$ of the label claim, was in the ranges 95.56-96.27\% for isomer I and 97.10-97.89\% for isomer II. The LOD and LOQ for isomer I of perindopril L-arginine were 0.1503 and $0.4555 \mu \mathrm{g} \mathrm{mL}^{-1}$ while those for isomer II 0.0356 and $0.1078 \mu \mathrm{g} \mathrm{mL}^{-1}$, respectively.

The best separation of the cis/trans isomers of perindopril L-arginine was obtained for the above-mentioned chromatographic parameters. The robustness of the UHPLCDAD procedure was evaluated after changing the mobile phase composition (acetonitrile volume, $20 \pm 5 \mathrm{v} / \mathrm{v}$ ), mobile phase $\mathrm{pH}$ (formic acid concentration, 3-0.05\%),
Table 1 Validation parameters of linearity of isomer I and isomer II of perindopril L-arginine

\begin{tabular}{lll}
\hline & Isomer I & Isomer II \\
\hline Retention time $(\min )$ & 1.76 & 1.95 \\
Range of linearity $\left(\mu \mathrm{g} \mathrm{mL}{ }^{-1}\right)$ & $0.40-1.40$ & $0.40-2.40$ \\
Regression equation $(y)$ & & \\
Slope $\left(\mathrm{a} \pm S_{\mathrm{a}}\right)$ & $0.21 \pm 0.04$ & $1.77 \pm 0.03$ \\
Intercept $\left(\mathrm{b} \pm S_{\mathrm{b}}\right)$ & $0.02 \pm 0.04$ & $0.01 \pm 0.04$ \\
$\mathrm{LOD}\left(\mu \mathrm{g} \mathrm{mL}^{-1}\right)$ & 0.1503 & 0.0356 \\
LOQ $\left.(\mu \mathrm{g} \mathrm{mL})^{-1}\right)$ & 0.4555 & 0.1078 \\
Correlation coefficient $(r)$ & 0.9914 & 0.9998 \\
\hline
\end{tabular}

$S_{a}$ standard deviation of slope, $S_{b}$ standard deviation of intercept, $t$, calculated values of Student's $t$ test, $t_{\alpha, f}=2.1709$ critical values of Student's test for degrees of freedom $f=11$ and significance level $\alpha=0.05$

Table 2 System suitability tests of the UHPLC-DAD

\begin{tabular}{lll}
\hline Parameter & Isomer I & Isomer II \\
\hline Relative standard deviation of peak area $\%$ & 1.84 & 1.50 \\
$\begin{array}{l}\text { Relative standard deviation of retention } \\
\quad \text { time (min) \% }\end{array}$ & 0.02 & 0.02 \\
Resolution & 1.68 & 1.47 \\
Asymmetry (tailing factor) & 1.83 & 1.51 \\
Number of theoretical plates & 34,693 & 28,716 \\
\hline
\end{tabular}

Resolutions were calculated between two adjacent peaks in nodegraded and degraded samples

flow rate $\left(1.0 \pm 0.1 \mathrm{~mL} \mathrm{~min}^{-1}\right)$, absorption wavelength $(353 \pm 3 \mathrm{~nm})$ and column temperature $\left(25 \pm 10^{\circ} \mathrm{C}\right)$. No statistically significant differences were established for the parameters studied in the investigation of robustness as their deviation did not exceed the permissible range of $\pm 2 \%$. While higher changes in these parameters resulted in the lack of separation of the isomers and the appearance of tailing peaks. System suitability was examined in regard to the relative standard deviation for peak areas and peak times, peak resolution, peak asymmetry and the number of theoretical plates. All parameters are collected in Table 2.

\section{Conclusion}

Since the UHPLC-DAD method presented in this communication is a simple, accurate, selective and time-saving tool for the determination of the cis/trans isomers of perindopril L-arginine, which also allows good separation, it can be used for routine testing and stability analysis of that compound. In addition, the method was validated for compliance with ICH guidelines and proved to meet the acceptance criteria. It may, therefore, be recommended for 
quality evaluation of perindopril L-arginine in the commercial product Prestarium ${ }^{\circledR}$, including determination of its cis/trans isomers.

Acknowledgments This study was supported by Grant from the Ministry of Science and Higher Education (Diamentowy Grant DI2012 024342).

Open Access This article is distributed under the terms of the Creative Commons Attribution License which permits any use, distribution, and reproduction in any medium, provided the original author(s) and the source are credited.

\section{References}

1. Remkova A, Kratochvilova H, Durina J (2008) Hypertens 22:338-644

2. Pascard C, Guilhem J, Vincent M, Remond B, Portevin B, Laubie M (1991) J Med Chem 34:663-669
3. Lecocq B, Funck-Brentano C, Lecocq V, Ferry A, Gargin M, Devissaguet M, Jaillon P (1990) Clin Pharmacol Ther 47:397-402

4. Telejko E (2007) Curr Med Res Opin 23:953-960

5. Bouabdallah S, Trabelsi H, Ben Dhia M, Ben Hamida N (2012) Chromatogr 75:1247-1255

6. Dugga HH, Peraman R, Nayakanti D (2014) J Chromatogr Sci 52(4):315-320

7. Medenica M, Ivanovic D, Maskovic M, Jancic B, Malenovic A (2007) J Pharma Biomed Anal 44:1087-1094

8. Simoncic Z, Roskar R, Gartner A, Kogej K, Kmetec V (2008) Int J Pharm 356:200-205

9. Remko M (2009) Eur J Med 44(1):101-108

10. Gumustas M, Ozkan SA (2013) J AOAC Int 96(4):751-757

11. Validation of analytical procedures, Proceeding of the International Conference of Harmonisation (ICH), Commission of the European Communities (1996) 